\title{
Investigation on "Chinese Spirit" of Architectural Students in Higher Vocational Colleges
}

\author{
Huifang Guo a, ${ }^{\text {*, }}$ Fangfang Yin ${ }^{\mathrm{b}}$, Denghong Wang ${ }^{\mathrm{c}}$ \\ Zhejiang Tongji Vocational College of science and technology, Hangzhou, Zhejiang 3112312 , \\ China \\ a, *32970400@qq.com, b 61681034@qq.com, c782851368@qq.com
}

\begin{abstract}
At the beginning of 2020, China suffered a sudden epidemic, in which many extraordinary stories occurred. These stories in extraordinary times have stronger appeal to people than usual. In order to investigate which "Chinese spirit" stories have the deepest impact on higher vocational students, as well as the communication path of "Chinese spirit" loved by students and the effect of integrating "Chinese spirit" into classroom ideology and politics, a questionnaire was issued to architectural students to fully grasp the impact of "Chinese spirit" on higher vocational students. The results show that the most impressed "Chinese spirit" figures are medical personnel. Most students understand and agree with the "Chinese spirit", think that patriotism and "helping each other in the same boat" can best represent the Chinese spirit, and think that the integration of the "Chinese spirit" into classroom teaching has had a positive impact on them.
\end{abstract}

Keywords: Chinese Spirit; Epidemic Situation; Higher Vocational Students; Impact Research; Curriculum; Ideological and Political Education.

\section{Foreword}

In early 2020, a sudden epidemic swept the world. Since the novel coronavirus pneumonia epidemic situation, after the unanimous efforts of the whole party, army and people of all nationalities, the epidemic situation in the country has been fully controlled, and the production and living order has basically returned to normal. Xijinping pointed out that "the Chinese people's Chinese strength, Chinese spirit, Chinese efficiency and the image of a responsible big country in epidemic prevention and control have been highly praised by the international community". Since the outbreak of the war of prevention and control, the 1.4 billion people of the country have worked together with one heart, united as one city and in the same boat to unite the Chinese spirit admired and admired by the world.

During the epidemic, many touching stories of "Chinese spirit" took place. These stories in extraordinary times have stronger appeal to people than usual. Especially the students who are experiencing these stories can understand these stories more deeply and change their behavior by taking the protagonist of the story as an example. In order to fully understand the impact of the Chinese spirit on higher vocational students, a questionnaire was issued to architectural students to understand college students' awareness of the Chinese spirit and the impact of the Chinese spirit on them.

\section{Nvestigation on College Students' Cognition of "Chinese Spirit"}

According to the survey, $98.83 \%$ of the students realized the Chinese spirit. Among them, 36.07\% of the students can describe the Chinese spirit in detail, and $52.22 \%$ of the students know the core content of the Chinese spirit. $36.07 \%$ of the students knew and could tell the content of Chinese spirit in detail, and $52.22 \%$ knew the core content of Chinese spirit.

The "Chinese spirit" experienced by the students in the epidemic includes patriotism, unity, love and dedication, loyalty, hard work, reform and innovation, responsibility, diligence and courage, courage to take responsibility, humility and humility. Among them, the students believe that the most important core of the Chinese spirit is patriotism. 


\section{An Investigation on the Influence of Chinese Spirit on College Students' Beliefs}

A man without spirit will not stand, and a country without spirit will not be strong. Xijinping pointed out: "spirit is the soul of a nation for long-term survival. Only when the spirit reaches a certain height can the nation stand tall and move forward bravely in the torrent of history. Many extraordinary" Chinese spirit "stories have taken place in the epidemic. The great" Chinese spirit "contained in these extraordinary stories, it has brought a profound ideological impact to college students who have experienced the epidemic. These "Chinese spirit" can enhance college students' patriotic enthusiasm and strengthen their ideals and beliefs.

\subsection{Which Words can Best Express the "Chinese Spirit" in the Hearts of Higher Vocational Students}

According to the survey, during the epidemic, the students believe that "helping each other in the same boat, fearing difficulties and dangers, fighting tenaciously and respecting science" can best reflect the Chinese spirit during the epidemic. Among them, the students believe that the word that can best express the Chinese spirit is "helping each other in the same boat".

Table 1. Statistics on expressions of "Chinese spirit" vocabulary in the minds of vocational students

\begin{tabular}{|c|c|}
\hline option & proportion \\
\hline to pull together in times of trouble & $96.25 \%$ \\
\hline help one another in defense work & $85.25 \%$ \\
\hline Defy difficulties and dangers & $87.35 \%$ \\
\hline Tenacious struggle & $81.50 \%$ \\
\hline Respect science & $70.96 \%$ \\
\hline other & $0.47 \%$ \\
\hline
\end{tabular}

\subsection{The People and Things Most Impressed by Higher Vocational Students in the Epidemic}

(1) Medical workers

According to the survey, the students who think they have the deepest impression of "medical workers" account for the largest proportion. Many students wrote: "take the initiative to fight", "not afraid of danger", "mask strangulation", "female nurses shave their heads", "sleep standing", "sleep against the wall" and so on.

(2) Grassroots workers

During the epidemic, the students were deeply moved by "grass-roots workers serving the community and village day and night" and "father went to the village to participate in epidemic prevention".

(3) Construction of Huoshen mountain and Leishen mountain hospitals

Huoshenshan hospital, with a total construction area of 33900 square meters and a capacity of 1000 beds, was successfully built in only 10 days, which made the students feel the strength and speed of China and the spirit of the Chinese people to fight the epidemic in unity.

(4) Academician Zhong Nanshan, Academician Li Lanjuan and other scientific and technological workers

"Academician Zhong Nanshan crowded the high-speed railway dining car to Wuhan", "Academician Li Lanjuan set out on the front line of anti-epidemic", "researchers forgot to eat and sleep and studied vaccines" inspired the students' determination to study hard and serve the motherland.

(5) Speed and effect of epidemic control in China 
"China's treatment of the epidemic situation is very different from that of foreign countries", "China is the country with the best epidemic prevention and control, and is proud to live as a Chinese!" and so on, which gave the students a sense of national pride.

(6) Home is also a contribution to the epidemic

(7) The general secretary visited Hubei personally to direct the anti-epidemic work

(8) Teenagers studying in the shelter hospital

(9) Volunteer yourself

(10) The teacher is very dedicated to online classes

\subsection{What Ideas have the "Chinese Spirit" in the Epidemic Brought to the Students}

According to the survey, $84.54 \%$ of the students thought that the Chinese spirit in the epidemic had a great impact on them. $93.68 \%$ of the students "feel proud of the motherland", $84.54 \%$ of the students expressed their gratitude to the front-line anti epidemic personnel, and $82.67 \%$ of the students said "study hard and become useful to the society".

\subsection{How do Contemporary Youth Reflect Their Responsibilities and Responsibilities in the Epidemic}

According to the survey, students believe that "do not believe or spread rumors", "strengthen exercise and improve their immunity", "study hard and do not stop classes" can best reflect their responsibilities and responsibilities.

Table 2. The performance of responsibility and accountability in the epidemic

\begin{tabular}{|c|c|}
\hline option & proportion \\
\hline Don't believe rumors, don't spread rumors & $94.61 \%$ \\
\hline Study hard and do not stop classes & $87.12 \%$ \\
\hline Strengthen exercise and improve your immunity & $88.29 \%$ \\
\hline Exercise perseverance and the will to advance in the face of difficulties & $83.37 \%$ \\
\hline Contribution to epidemic prevention within one's ability & $79.63 \%$ \\
\hline other & $2.34 \%$ \\
\hline
\end{tabular}

\subsection{During the Epidemic, What Behaviors have College Students Done to Reflect the "Chinese Spirit"}

Table 3. During the epidemic, the behavior of college students embodying the "Chinese spirit"

\begin{tabular}{|c|c|}
\hline option & proportion \\
\hline Donate materials to areas with serious epidemic situation & $55.27 \%$ \\
\hline Refuse to eat wild animals and protect nature & $80.33 \%$ \\
\hline Help people around you master the necessary epidemic prevention measures & $76.81 \%$ \\
\hline Cheer for the front-line medical staff through the network platform & $70.73 \%$ \\
\hline Participate in community volunteer service & $44.96 \%$ \\
\hline Actively exercise and bring positive energy to the society & $63.23 \%$ \\
\hline Popular science epidemic prevention knowledge & $61.12 \%$ \\
\hline Try to stay at home and reduce going out & $72.37 \%$ \\
\hline Comply with the requirements of the state, community and school during epidemic prevention & $65.34 \%$ \\
\hline other & $1.17 \%$ \\
\hline
\end{tabular}


Volume 14 (2021)

According to the survey, during the anti-epidemic period, $80.33 \%$ of the students "refuse to eat wild animals", $76.81 \%$ of the students help the people around them master the necessary protective measures, and $72.37 \%$ of the students "try to stay at home and reduce going out".

\section{Research on the Influence of the Integration of "Chinese Spirit" into Classroom Teaching on Higher Vocational Students}

From the end of February to the beginning of May 2020, due to the needs of epidemic prevention and control, students cannot return to the campus for learning. In order to ensure "non-stop teaching and non-stop school", the school provides rich educational resources and guides students' learning by carrying out online teaching and using the Internet platform. Internet teaching lacks the atmosphere of face-to-face interaction, and its appeal to students is slightly weaker than face-to-face teaching. Due to the lack of school teaching atmosphere, students' learning will inevitably be affected. Students studying at home need stronger learning motivation and enhance their willingness to learn actively. And the stronger learning power comes from the ideological motivation. Marx said, "in order to realize thought, there must be people who use the power of practice". Teachers are the main body of teaching and educating people. Teachers' integration of political thought in the classroom is a very important means to stimulate students' learning progress. Through the curriculum of "moistening things silently", students' thirst for knowledge can be enhanced.

Many touching stories happened during the epidemic. These stories happened in extraordinary times have stronger appeal to people than usual. Especially the students who are experiencing these stories can understand these stories more deeply. Integrating these "Chinese spirit" into curriculum thought and politics can give better play to the incentive effect of "Chinese spirit" on students.

\subsection{The Combination of "Chinese Spirit" and Classroom Teaching Expected by College Students}

According to the survey, students prefer the combination of "Chinese spirit" and classroom teaching, such as "stories", "character examples", "playing videos", "teaching by example", "practical activities", "teacher-student interaction", "engineering cases", etc.

\subsection{What Professional Knowledge do College Students Think "Chinese Spirit" can be Combined With}

According to the survey, the students believe that the "Chinese spirit" can be integrated into: "construction engineering", "engineering construction", "construction technology", "construction materials", "installation", "hydraulics", "road engineering", "architecture, design and management", "cost", "materials", "water supply and drainage", "engineering economy", "final settlement of completion", "pricing", "map reading" "CAD", "Mechanics", "bridge and culvert engineering", "measurement", "steel structure", "PC assembly", "decoration", "data management", "building safety", "architectural design", "structure", "epidemic prevention house type" and other professional knowledge points. At the same time, it is considered that "Chinese spirit" can be closely combined with courses such as "Introduction to Mao Zedong Thought" and "Ideological and political cultivation".

\subsection{The Impressive Teachers of College Students Integrate into the "Chinese Spirit" of Classroom Teaching}

According to the survey, the "Chinese spirit" in the classroom teaching impressed the students are: "Huoshen mountain construction video", "the hard struggle of front-line medical personnel", "China's speed of epidemic control", "epidemic news sharing", "examples of Leishen Mountain hospital", "patriotic film", "academician Zhong Nanshan's anti epidemic deeds", "Wuhan doctor's deeds" "China speed", "Hong Kong Zhuhai Macao Bridge", "inspirational film", "home is also a contribution", "advance in the face of difficulties", "deeds of front-line medical staff", "the first lesson 
at the beginning of school", "how to overcome the difficulties encountered in practical engineering cases by using the Chinese spirit", "unity in training", "the country is becoming stronger and stronger", "the assembled structure of Huoshen mountain and Leishen mountain" "House type design should be combined with epidemic prevention requirements and incorporate patriotic elements", etc.

\subsection{The Influence of the Construction of Leishen Mountain and Huoshen Mountain Hospitals on Students Majoring in Architecture}

According to the survey, the students believe that the construction of Leishen mountain and Huoshen Mountain hospital has made them feel: "China's power", "China's speed", "China's greatness", "the power of unity", "China's strength", "China's rise", "believe in China", "multiple possibilities of construction" and "a new understanding of China's infrastructure capacity" "The importance of the national construction industry, the greatness of Chinese construction workers", "I feel the rapid development of China's science and technology", "national pride", "I am very proud of being a Chinese", "the superiority of the socialist system", "there are no insurmountable difficulties", "I fully recognize the importance of prefabricated architecture" and "increase my understanding of my major" "I love the construction industry more", "our construction is getting better and better", "we are more passionate about our profession", "we should love life more when we move forward with their weight".

The students realized that "time is money", "studying hard is true", "a strong youth makes a strong country", and said they should "study hard", "work hard", "strengthen the study of professional knowledge and serve the motherland", "I also want to study hard and become a meaningful person" "We should study hard, learn professional knowledge well and contribute to the motherland", "we should also pay attention to efficiency in doing things".

\subsection{The Integration of Chinese Spirit into Classroom Teaching has had a Positive Impact on College Students}

According to the survey, $98.59 \%$ of students believe that the integration of Chinese spirit into classroom teaching has had a positive impact on them.

Table 4. Most students think that the integration of Chinese spirit into classroom teaching has a positive impact on them

\begin{tabular}{|c|c|}
\hline option & proportion \\
\hline good & $98.13 \%$ \\
\hline not good & $1.87 \%$ \\
\hline
\end{tabular}

\section{Conclusion}

By investigating the impact of "Chinese spirit" on Higher Vocational Students in the epidemic situation, it can play an important role in the sublimation and utilization of the follow-up "Chinese spirit". By investigating the impressive stories of "Chinese spirit" in the epidemic situation, the channels for students to understand the "Chinese spirit" and the characteristics of study and life during the epidemic situation, we can better carry out the "Chinese spirit" The work of integrating into the spiritual world of higher vocational students. Through the investigation, it is found that the students feel and understand the "Chinese spirit" in the epidemic situation. The students believe that the "Chinese spirit" has a good effect in integrating into classroom teaching. The "Chinese spirit" in the epidemic situation has a good incentive effect on the students. The students are "proud of their motherland" and express their desire to "Study hard and become useful to society". It can be seen that the integration of "Chinese spirit" into classroom teaching, campus culture and network publicity can play a good effect. 


\section{Acknowledgments}

This paper is supported by Zhejiang Zhonghua Vocational education scientific research project in 2021 (ZJCV2021E44): Investigation and Analysis on the cultivation of craftsman spirit in architecture specialty and Research on practical countermeasures.

\section{References}

[1] Wang Ya. Study on anxiety level of college students and its influencing factors during epidemic prevention and control [J]. Journal of teacher education, 2020,7 (03): 76-83. Doi: 10.13718/j. cnki. jsjy. 2020.03.009.

[2] Zhang Zhidan. Basis, connotation and value of anti-epidemic spirit [J]. Research on Ideological and political education, 2020,36 (04): 24-31. Doi: 10.15938/j.cnki.iper.2020.04.005.

[3] Yang Lan, Geng Bujian. Research on the connotation of anti-epidemic spirit and its integration into school ideological and Political Education [J]. Theoretical construction, 2020,36 (05): 7-14. Doi: 10.19810/j. issn. 1007- 4767.2020.05.002.

[4] Wang Yi. Carrying forward the great anti epidemic spirit and highlighting the advantages of the socialist system with Chinese characteristics [J]. Teaching and research, 2020 (12): 5-14.

[5] Chen Xue, Wang Yonggui. Chinese spiritual war: a powerful spiritual force in the struggle against "epidemic disease" [J]. Research on Ideological and political education, 2020,36 (04): 37-41. Doi: 10. 15938/ j. cnki. iper.2020.04.007. 